\title{
Characteristics and Early Diagnosis of Gastric Cancer Discovered after Helicobacter pylori Eradication
}

\author{
Masanori Ito ${ }^{1}$, Shinji Tanaka², and Kazuaki Chayama ${ }^{3}$ \\ Departments of ${ }^{1}$ General Internal Medicine, ${ }^{2}$ Endoscopy, and ${ }^{3}$ Gastroenterology and Metabolism, Hiroshima University Hospital, \\ Hiroshima, Japan
}

\author{
Article Info \\ Received December 11, 2019 \\ Revised March 4, 2020 \\ Accepted March 7, 2020 \\ Published online April 24, 2020 \\ Corresponding Author \\ Masanori lto \\ ORCID https://orcid.org/0000-0002-8218-9059 \\ E-mail maito@hiroshima-u.ac.jp
}

\begin{abstract}
The prevalence of gastric cancer after eradication (GCAE) is increasing dramatically in Japan. GCAE has characteristic features, and we must understand these features in endoscopic examinations. Differentiated cancer types were frequently found after eradication and included characteristic endoscopic features such as reddish depression (RD). However, benign RD can be difficult to distinguish from gastric cancer because of histological alterations in the surface structures (nonneoplastic epithelium or epithelium with low-grade atypia [ELA]) as well as multiple appearances of RD. Recently, we clarified similar alterations in genetic mutations between ELA and gastric cancer, suggesting that ELA is derived from gastric cancer. Clinically, submucosal invasive cancer was frequently found in patients after eradication therapy even if they received annual endoscopic surveillance. We can improve the diagnostic ability using image-enhanced endoscopy with magnified observation. (Gut Liver 2021;15:338-345)
\end{abstract}

Key Words: Stomach neoplasms; Eradication therapy; Helicobacter pylori; Reddish depression; Epithelium with low-grade atypia

\section{INTRODUCTION}

Gastric cancer is the fifth most common cancer and the third leading cause of cancer death worldwide, accounting for nearly three-quarters a million deaths annually. ${ }^{1}$ Helicobacter pylori infection plays an important role in gastric carcinogenesis. In 1994, the International Agency for Research on Cancer recognized that $H$. pylori is a definite carcinogen for gastric cancer development. ${ }^{2}$ In Japan, Uemura et al. ${ }^{3}$ demonstrated that gastric cancer developed only in patients with $H$. pylori infection using a prospective cohort study. We retrospectively reviewed our gastric cancer patients and demonstrated that the prevalence of $H$. pylori-negative gastric cancer was extremely rare $(0.66 \%$, $21 / 3,161) .{ }^{4}$ In addition, Ono et al. ${ }^{5}$ reported prevalence of $H$. pylori-negative gastric cancer was less than $1 \%$ in Japanese patients. These studies indicated that $H$. pylori infection is a crucial factor in gastric carcinogenesis in Japan.
In 2013, the Japanese government approved that national health insurance can cover $H$. pylori eradication therapy for patients with $H$. pylori-associated gastritis. For diagnosis of $H$. pylori-associated gastritis, endoscopic diagnosis of $H$. pylori-induced gastritis is essential prior to eradication therapy. At present, 1.5 million courses of eradication therapy have been carried out in Japan. ${ }^{6}$ This indicates that primary prevention of gastric cancer has started in Japan.

Along with the increase in eradication therapy, mortality from gastric cancer is now decreasing gradually. However, eradication therapy has caused another crucial problem, namely the problem of gastric cancer after eradication therapy (GCAE). Gastric cancer develops in some patients even after successful eradication therapy, and recent studies have been clarifying its characteristic features. In the present review, we examine some problems around GCAE and propose effective clinical practices for the diagnosis and treatment for GCAE. 
PREVALENCE OF GASTRIC CANCER DISCOVERED AFTER ERADICATION THERAPY

Many studies have indicated that eradication therapy for $H$. pylori diminishes the prevalence of gastric cancer development. ${ }^{7}$ In 1997, Uemura et al. ${ }^{8}$ demonstrated that the prevalence of gastric cancer decreased in patients with successful eradication therapy in a non-randomized prospective study. In 2008, the results of a Japanese multicenter study were published and demonstrated the prevalence of secondary gastric cancer diminished by one-third using successful eradication therapy. ${ }^{9}$ Recently, the effect of eradication therapy has been shown in some systematic reviews from Western countries as well as from East Asia including Japan. ${ }^{10-14}$ Lee et al. ${ }^{10}$ demonstrated that eradication provided significant benefit for asymptomatic infected individuals (pooled incidence rate ratio, $0.62 ; 95 \%$ confidence interval [CI], 0.49 to 0.79 ) and individuals after endoscopic resection of gastric cancers (pooled incidence rate ratio, $0.46 ; 95 \% \mathrm{CI}, 0.35$ to 0.60 ). Likewise, Doorakkers et al. ${ }^{11}$ showed the pooled relative risk of gastric cancer was 0.46 (95\% CI, 0.32 to 0.66 ) favoring eradication therapy. Sugano ${ }^{14}$ also demonstrated that a H. pylori eradication group showed a significantly lower risk of gastric cancer development (odds ratio [OR], 0.46; 95\% CI, 0.39 to 0.55 ), and especially emphasized that the beneficial effect of eradication was greater in Japan (OR, 0.39; 95\% CI, 0.31 to 0.49). Most recently, a Korean prospective, double-blind, placebocontrolled, randomized trial clearly showed that patients with early gastric cancer who received $H$. pylori treatment had lower rates of metachronous gastric cancer (hazard ratio in the treatment group, $0.50 ; 95 \% \mathrm{CI}, 0.26$ to $0.94 ; \mathrm{p}=0.03) .{ }^{15}$

\section{WHEN DID GASTRIC CANCER DEVELOP IN PATIENTS AFTER SUCCESSFUL ERADICATION?}

First of all, we have to understand the pathogenesis of GCAE. Did GCAE newly develop after eradication therapy or was it already existing before eradication therapy? Clinical features in cases with GCAE, especially the gender of patients and tumor location in the stomach, were reported to be similar to those with conventional gastric cancer (with H. pylori infection ${ }^{16}$ but different from those without $H$. pylori infection. ${ }^{17}$ In addition, the natural history of mucosal gastric cancer with differentiated histology was reported as slow-growing as expected, for example, doubling time was reported as 16.6 months by radiological evaluation. ${ }^{18,19}$ These findings strongly suggested that the majority of GCAE, detected in the present real-world study, had already developed before eradication therapy. ${ }^{20}$

\section{ENDOSCOPIC FEATURES OF GASTRIC CANCER DISCOVERED AFTER ERADICATION THERAPY}

We have to recognize that GCAE revealed representative endoscopic feature, namely a superficial depressed feature. ${ }^{16,21-23}$ In 2005, we reported the morphological alterations of gastric tumors after eradication therapy of $H$. pylori in a prospective intervention study. ${ }^{24}$ Patients with a gastric tumor received eradication therapy and the features of the gastric tumors were re-examined. Surprisingly, after successful eradication, 50\% adenomas and $24 \%$ adenocarcinoma became flat and indistinct. ${ }^{24}$ This phenomenon seemed to be compatible with the endoscopic features of GCAE.

The true pathogenesis of tumor flattering is still unknown. We speculated that a decreased level of serum gastrin may be a reason for this phenomenon. Gastrin is a growth factor for epithelial cells, ${ }^{25,26}$ and we previously detected the gastric receptor in gastric epithelial cells and gastric cancer cells. ${ }^{27,28}$ Serum gastrin levels were decreased by eradication therapy in patients with atrophic gastritis; ${ }^{29}$ therefore, proliferating signals through the gastrin receptor may decline in response to the eradication system followed by flattering the tumor tissue. ${ }^{30}$ Decreases in cytokine levels in response to eradication therapy may be another reason for the inhibition of tumor growth and flattering of the tumor tissue. ${ }^{31,32}$

\section{HISTOLOGIC FEATURES OF GASTRIC CANCER DISCOVERED AFTER ERADICATION THERAPY}

We further found that endoscopic alteration was closely linked to histological features. After eradication, a normal or mild-atypical epithelium appeared on the surface of gastric tumor tissues just covering the tumor tissue. ${ }^{30}$ After eradication, we found almost normal epithelium on the surface of adenoma tissue and slightly atypical epithelium on the surface of gastric cancer tissue. ${ }^{30}$ This may be a reason why gastric tumors become indistinct after eradication therapy.

In cases with gastric adenoma, Gotoda et al. ${ }^{33}$ first reported indistinct features after eradication therapy. In our previous study, $50 \%$ of gastric adenomas became indistinct and normal epithelium appeared in $75 \%$ of all adenomas. ${ }^{34}$ Recently, Suzuki et al. ${ }^{35}$ reported that $26 \%$ of adenomas revealed histological complete regression after eradication therapy.

On the other hand, we could find slightly atypical (not completely normal) epithelium covering gastric cancer 
tissue (Fig. 1). We named this feature as epithelium with low-grade atypia (ELA) and defined it according to the following criteria: (1) ELA must lie on the surface of gastric cancer tissue; (2) ELA must be columnar epithelium with spindle or oval nuclei; (3) nuclear polarity must be present in the ELA; and (4) the ELA must be separated and distinguished from the surrounding nonneoplastic mucosa. ${ }^{36}$ Previously, we have presented that ELA appeared not only on gastric cancer after $H$. pylori-eradication but on that with $H$. pylori infection. However, the degree of ELA was statistically higher on $H$. pylori-eradicated cancer than on H. pylori-infected cancer. ${ }^{36}$ These histological features were confirmed in several studies mainly from Japan, and this histology was also called "nonneoplastic epithelium."37-39

Furthermore, we examined the pathogenesis of this epithelium. Small numbers of nonneoplastic glands were detected within the gastric cancer tissue, and these glands were recognized as nonneoplastic without difficulty. However, we also detected another type of epithelium termed ELA, which was different from both nonneoplastic epithelium and tumor tissue, on the tumor surface. It should be clarified whether ELA comes from normal tissue (indicating that ELA is from regenerative changes from nonneoplastic epithelium) or tumor tissue (where ELA comes from the re-differentiation of gastric cancer by eradication). We extracted DNA from gastric cancer tissue, normal gastric mucosa, and ELA by laser-microdissection. ${ }^{40}$ We used the NCC Oncopanel (National Cancer Center and Sysmex Cancer Innovation Laboratory, Tokyo, Japan) and examined gene alterations for 125 genes using deep-sequencing. ${ }^{41}$ The mutation profile of ELA was quite similar to that in gastric cancer tissue, suggesting that ELA was derived from gastric cancer tissue, and gastric cancer tissue can be histologically restored by eradication therapy. ELA was not from normal epithelium contaminating the tumor tissue but from gastric cancer tissue. In animal model, adenocarcinoma tissue can be restored by genetic manipulation. ${ }^{42}$ This may be a first report describing that human gastric cancer tissue can be histologically restored by eradication therapy.

\section{CLINICAL IMPACT OF HISTOLOGICAL CHARACTERISTICS IN THE DIAGNOSIS GASTRIC CANCER DISCOVERED AFTER ERADICATION THERAPY}

Clinically, this phenomenon is supposed to evoke the difficulty in endoscopic diagnosis of GCAE as well as the gastric adenomas described above. Previously, we reported that submucosal invasive GCAE showed extensive ELA on the surface of gastric cancer tissue in patients receiving annual endoscopic examination after eradication. ${ }^{36}$ The appearance of ELA may interrupt the detection of GCAE in earlier stages, as a result these tumors are likely to be detected at more advanced stages. Moreover, it has been reported that there is a noticeably increased prevalence of GCAE showing submucosal invasion compared with that for $H$. pylori-positive cancers. ${ }^{43-45}$

Thereafter, we retrospectively analyzed the clinicopathological characteristics of GCAE patients who received annual endoscopic examinations after eradication, and compared incident of gastric cancer with submucosal invasion between GCAE and controls. The prevalence of early gastric cancer with submucosal invasion was significantly higher in the eradicated group than in the control group after propensity score matching $(16.0 \%$ vs $4.9 \%$, respectively; $\mathrm{p}=0.021$ ) (Table 1$).{ }^{45,46}$ We could not detect a statistically significant difference in any features, including sex, age, previous cancer history, location, macroscopic type, and tumor size between two groups. ${ }^{46} \mathrm{H}$. pylori eradication therapy increased the prevalence of differentiated-type
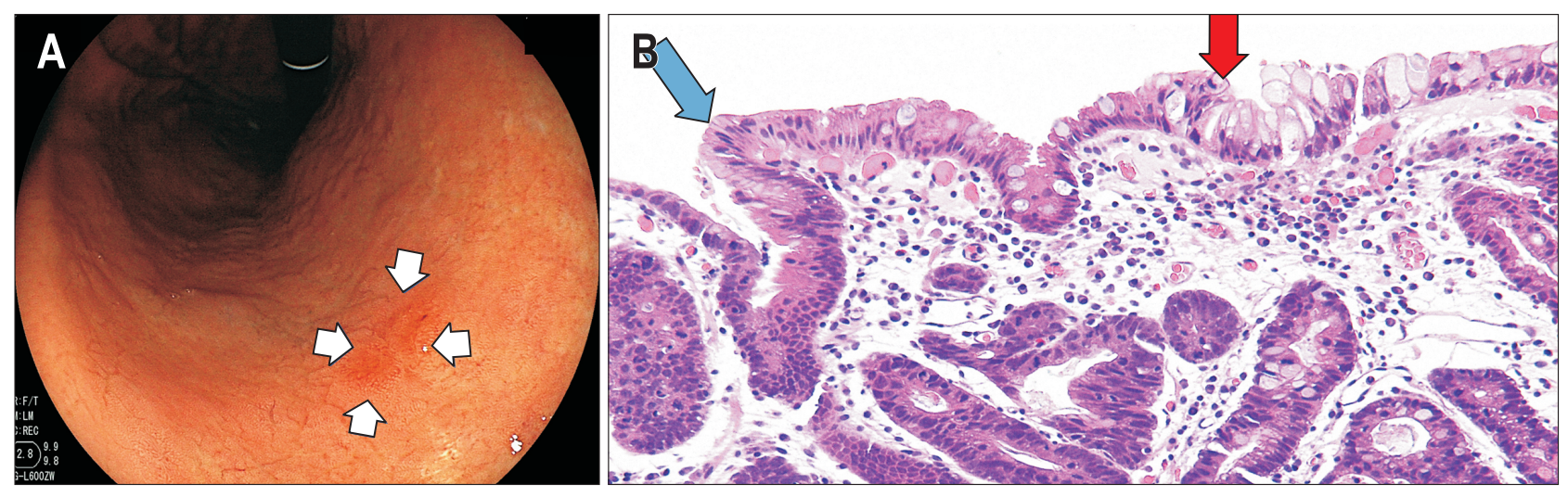

Fig. 1. The patient was a woman in her 60s. (A) A reddish depressed lesion (arrows) was observed on the lesser curvature of the gastric corpus. (B) Histologically, low-grade atypia (between the blue and red arrows) covered the surface of the tumor tissue. Tumor tissue and normal epithelium were noted on the left side of the blue arrow and on the right side of the red arrow, respectively. 
gastric cancer with submucosal invasion despite patients' completion of annual endoscopic screening after eradication.

\section{IMPORTANCE OF EARLY DETECTION OF GASTRIC CANCER DISCOVERED AFTER ERADICATION BY ENDOSCOPIC SURVEILLANCE}

For accurate endoscopic examination in patients with successful eradication, we have to understand that the typical endoscopic features of GCAE were reddish depression (RD). Diffuse redness, which is a typical feature of H. pylori-associated gastritis, ${ }^{47}$ disappears after successful eradication, and cancer lesions become relatively reddish. However, these RDs can also be found in non-cancer stomachs and are termed mottled patchy redness ${ }^{48}$ or map-

Table 1. Prevalence of SM Invasive Cancer Discovered after Eradication Therapy

\begin{tabular}{lccc}
\hline Depth (SM invasion) & Eradicated & Control & p-value \\
\hline Maehata et al. $^{45}$ & $17 / 96(18)$ & $8 / 96(8)$ & 0.051 \\
Hata et al. & $13 / 81(16)$ & $4 / 81(5)$ & 0.021 \\
\hline
\end{tabular}

Data are presented as number/number (\%).

SM, submucosal. like redness. ${ }^{49}$ Although these lesions were reported to be frequently found in patients with gastric cancer, ${ }^{50}$ it should be mentioned these were not direct findings of gastric cancer itself.

First, we tried to diagnose malignant RD lesions (RDLs) with white-light imaging (WLI) based on reports described by Yao et al. ${ }^{51}$ Gastric biopsy was performed in patients in whom we identified an irregularity (heterogeneous color, irregular demarcation or spiny depressed lesion) in RDLs; however, positive predictive value of a gastric biopsy was only $1.7 \% .^{52}$ Next, we used magnifying narrow-band imaging (M-NBI) to diagnose RDL. Based on the vessel plus surface classification system, ${ }^{53}$ we evaluated microsurface pattern (MSP; regular or irregular) and microvascular pattern (MVP; regular, irregular or absent) as we reported previously. ${ }^{54}$ We performed gastric biopsy when the RDLs

Table 2. Comparison of the Diagnostic Efficacy of White Light Imaging and Magnifying NBI for GCAE

\begin{tabular}{lcc}
\hline & $\begin{array}{c}\text { Using white } \\
\text { light imaging } \\
(n=117)\end{array}$ & $\begin{array}{c}\text { Using } \\
\text { magnifying NBI } \\
(n=104)\end{array}$ \\
\hline Lesions needed biopsy & $83 / 117(71)^{*}$ & $21 / 104(20)^{*}$ \\
Positive predictive value of biopsy & $2 / 83(2)^{*}$ & $9 / 21(43)^{*}$ \\
\hline
\end{tabular}

Data are presented as number/number (\%).

$\mathrm{NBI}$, narrow-band imaging; GCAE, gastric cancer after eradication. ${ }^{*} p<0.01$ (between two groups).
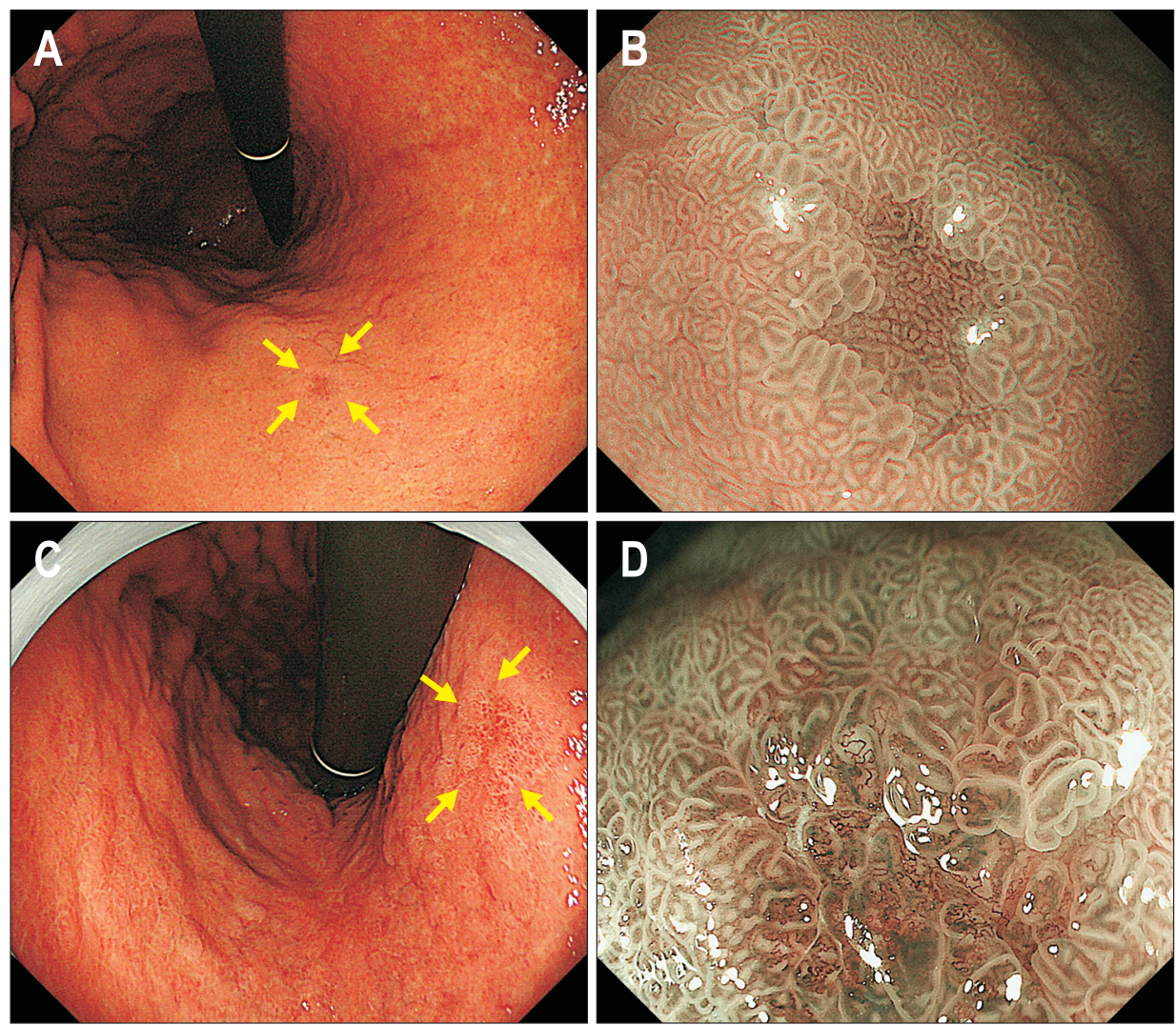

Fig. 2. The patients were a woman in her 60s without gastric cancer ( $A$, $B)$ and a man in his 60s with gastric cancer (well-differentiated tubular adenocarcinoma; C, D). Endoscopic image of a reddish depressed lesion acquired by white light endoscopy (A, C; indicated by the yellow arrows). By using magnifying narrow-band imaging, regular (B) or irregular (D) microsurface pattern and microvascular pattern were observed in each lesion. 
revealed an irregular MSP and/or irregular MVP within the demarcation line (Fig. 2).

In the M-NBI group, biopsy was performed in 21 patients (20\%), and nine were diagnosed as adenocarcinoma. Biopsy was required in fewer patients, and the positive predictive value of biopsy was statistically higher in the M-NBI group than in the WLI group (Table 2). ${ }^{52}$ These findings suggested that M-NBI demonstrated significantly superior diagnostic efficacy with respect to RDL to select malignant RD endoscopically. However, it may be difficult to diagnose these lesions only by WLI at present. For accurate diagnosis, we reported the usefulness of magnifying NBI methods. Recently, several reports from Japan described the usefulness of image-enhanced endoscopy in the diagnosis of GCAE. ${ }^{55-57}$

\section{POSSIBLE RISK STRATIFICATION FOR DEVELOPMENT OF GASTRIC CANCER DISCOVERED AFTER ERADICATION THERAPY AND EFFECTIVE SURVEILLANCE}

The final goal of our strategy was to diminish mortality from gastric cancer. Primary prevention by eradication therapy may be the best way to achieve our goal. The Japanese Society of Helicobacter Research demonstrated a total care program against $H$. pylori infection and gastric cancer screening. ${ }^{58}$ Careful follow-up will be necessary even after eradication therapy.

Risk stratification should be helpful for supplying effective surveillance of patients after eradication. Atrophic gastritis in the corpus or intestinal metaplasia is considered to be a risk factor for the development of GCAE. ${ }^{59-64}$ In 2015, the Kyoto Global Consensus Conference on $H$. pylori gastritis was held and the following statement was accepted: patients who remain at risk, as defined by the extent and severity of atrophy, should be offered endoscopic and histological surveillance (grade of recommendation: strong, evidence level: high, consensus level: $97.3 \%){ }^{65}$ In these cases, annual endoscopic surveillance may be necessary for early detection of gastric cancer.

In Japan, test-and-treat for $H$. pylori infection has spread in younger generations. This may be the best way to diminish gastric cancer death, however, the proper surveillance is not established for these subjects. Since these have little risk for gastric cancer development, annual endoscopic examination may be inappropriate. Recently, a molecular marker associated with DNA methylation has been investigated, and we hope a possible marker for the risk stratification and may be applied for these subjects in the near future. ${ }^{66-69}$

\section{CONFLICTS OF INTEREST}

No potential conflict of interest relevant to this article was reported.

\section{ORCID}

Masanori Ito https://orcid.org/0000-0002-8218-9059

Shinji Tanaka https://orcid.org/0000-0002-0480-3957

Kazuaki Chayama https://orcid.org/0000-0002-5530-5341

\section{REFERENCES}

1. International Agency for Research on Cancer (IARC). GLOBOCAN 2012 Estimated Cancer Incidence, Mortality and Prevalence Worldwide in 2012. IARC: Lyon, 2014.

2. Schistosomes, liver flukes and Helicobacter pylori. IARC Working Group on the Evaluation of Carcinogenic Risks to Humans. Lyon, 7-14 June 1994. IARC Monogr Eval Carcinog Risks Hum 1994;61:1-241.

3. Uemura N, Okamoto S, Yamamoto S, et al. Helicobacter pylori infection and the development of gastric cancer. N Engl J Med 2001;345:784-789.

4. Matsuo T, Ito M, Takata S, Tanaka S, Yoshihara M, Chayama K. Low prevalence of Helicobacter pylori-negative gastric cancer among Japanese. Helicobacter 2011;16:415-419.

5. Ono S, Kato M, Suzuki M, et al. Frequency of Helicobacter pylori-negative gastric cancer and gastric mucosal atrophy in a Japanese endoscopic submucosal dissection series including histological, endoscopic and serological atrophy. Digestion 2012;86:59-65.

6. Tsuda M, Asaka M, Kato M, et al. Effect on Helicobacter pylori eradication therapy against gastric cancer in Japan. Helicobacter 2017;22:e12415.

7. Ito M, Takata S, Tatsugami M, et al. Clinical prevention of gastric cancer by Helicobacter pylori eradication therapy: a systematic review. J Gastroenterol 2009;44:365-371.

8. Uemura N, Mukai T, Okamoto S, et al. Effect of Helicobacter pylori eradication on subsequent development of cancer after endoscopic resection of early gastric cancer. Cancer Epidemiol Biomarkers Prev 1997;6:639-642.

9. Fukase K, Kato M, Kikuchi S, et al. Effect of eradication of Helicobacter pylori on incidence of metachronous gastric carcinoma after endoscopic resection of early gastric cancer: an open-label, randomized controlled trial. Lancet 2008;372:392-397.

10. Lee YC, Chiang TH, Chou CK, et al. Association between Helicobacter pylori eradication and gastric cancer incidence: a systematic review and meta-analysis. Gastroenterology 
2016;150:1113-1124.

11. Doorakkers E, Lagergren J, Engstrand L, Brusselaers N. Eradication of Helicobacter pylori and gastric cancer: a systematic review and meta-analysis of cohort studies. J Natl Cancer Inst 2016;108:djw132.

12. Zhao B, Zhang J, Mei D, et al. Does Helicobacter pylori eradication reduce the incidence of metachronous gastric cancer after curative endoscopic resection of early gastric cancer: a systematic review and meta-analysis. J Clin Gastroenterol 2020;54:235-241.

13. Seta T, Takahashi Y, Noguchi Y, et al. Effectiveness of Helicobacter pylori eradication in the prevention of primary gastric cancer in healthy asymptomatic people: a systematic review and meta-analysis comparing risk ratio with risk difference. PLoS One 2017;12:e0183321.

14. Sugano K. Effect of Helicobacter pylori eradication on the incidence of gastric cancer: a systematic review and metaanalysis. Gastric Cancer 2019;22:435-445.

15. Choi IJ, Kook MC, Kim YI, et al. Helicobacter pylori therapy for the prevention of metachronous gastric cancer. N Engl J Med 2018;378:1085-1095.

16. Matsuo T, Ito M, Tatsugami M, et al. Gastric cancer development after Helicobacter pylori eradication therapy: a new form of gastric neoplasia. Digestion 2012;85:61-67.

17. Kiso M, Yoshihara M, Ito $M$, et al. Characteristics of gastric cancer in negative test of serum anti-Helicobacter pylori antibody and pepsinogen test: a multicenter study. Gastric Cancer 2017;20:764-771.

18. Haruma K, Suzuki T, Tsuda T, Yoshihara M, Sumii K, Kajiyama G. Evaluation of tumor growth rate in patients with early gastric carcinoma of the elevated type. Gastrointest Radiol 1991;16:289-292.

19. Matsui T, Yao T. Natural history of gastric cancer. Nihon Rinsho 2001;59 Suppl 4:583-588.

20. Ito M. Helicobacter pylori eradication for gastric cancer prevention. Expert Rev Anticancer Ther 2010;10:1-3.

21. Kamada T, Hata J, Sugiu K, et al. Clinical features of gastric cancer discovered after successful eradication of Helicobacter pylori: results from a 9-year prospective follow-up study in Japan. Aliment Pharmacol Ther 2005;21:1121-1126.

22. Kodama M, Okimoto T, Mizukami K, et al. Endoscopic and immunohistochemical characteristics of gastric cancer with versus without Helicobacter pylori eradication. Digestion 2018;97:288-297.

23. Nakagawa M, Sakai Y, Kiriyama Y, et al. Eradication of Helicobacter pylori induces immediate regressive changes in early gastric adenocarcinomas. Pathobiology 2019;86:135144.

24. Ito M, Tanaka S, Takata S, et al. Morphological changes in human gastric tumours after eradication therapy of Helicobacter pylori in a short-term follow-up. Aliment Pharmacol
Ther 2005;21:559-566.

25. Hayakawa Y, Chang W, Jin G, Wang TC. Gastrin and upper GI cancers. Curr Opin Pharmacol 2016;31:31-37.

26. Tahara E. Growth factors and oncogenes in human gastrointestinal carcinomas. J Cancer Res Clin Oncol 1990;116:121131.

27. Kumamoto T. Gastrin receptors in human gastric scirrhous carcinoma. Gastroenterol Jpn 1988;23:384-389.

28. Takamura A, Ito M, Boda T, et al. High expression of gastrin receptor protein in injured mucosa of Helicobacter pyloripositive gastritis. Dig Dis Sci 2013;58:634-640.

29. Naito Y, Ito M, Watanabe T, Suzuki H. Biomarkers in patients with gastric inflammation: a systematic review. Digestion 2005;72:164-180.

30. Ito M, Tanaka S, Maeda M, et al. Role of the gastrin-gastrin receptor system in the expansive growth of human gastric neoplasms. Digestion 2008;78:163-170.

31. Sasaki A, Kitadai Y, Ito M, et al. Helicobacter pylori infection influences tumor growth of human gastric carcinomas. Scand J Gastroenterol 2003;38:153-158.

32. Kitadai Y, Haruma K, Mukaida N, et al. Regulation of disease-progression genes in human gastric carcinoma cells by interleukin 8. Clin Cancer Res 2000;6:2735-2740.

33. Gotoda T, Saito D, Kondo H, et al. Endoscopic and histological reversibility of gastric adenoma after eradication of Helicobacter pylori. J Gastroenterol 1999;34 Suppl 11:91-96.

34. Ito M, Kotachi T, Boda T, et al. Endoscopic and histological feature of gastric cancer discovered after Helicobacter pylori eradication therapy; can the eradication therapy of Helicobacter pylori normalize gastric tumor? Stomach Intestine 2016;51:759-765.

35. Suzuki S, Gotoda T, Suzuki H, et al. Morphologic and histologic changes in gastric adenomas after Helicobacter pylori eradication: a long-term prospective analysis. Helicobacter 2015;20:431-437.

36. Kitamura Y, Ito M, Matsuo T, et al. Characteristic epithelium with low-grade atypia appears on the surface of gastric cancer after successful Helicobacter pylori eradication therapy. Helicobacter 2014;19:289-295.

37. Saka A, Yagi K, Nimura S. Endoscopic and histological features of gastric cancers after successful Helicobacter pylori eradication therapy. Gastric Cancer 2016;19:524-530.

38. Hori K, Watari J, Yamasaki T, et al. Morphological characteristics of early gastric neoplasms detected after Helicobacter pylori eradication. Dig Dis Sci 2016;61:1641-1651.

39. Nimura S, Saka A, Yagi K. Gastric cancer discovered after Helicobacter pylori eradication-Histopathological features. Stomach Intestine 2016;51:742-749.

40. Masuda K, Urabe Y, Ito M, et al. Genomic landscape of epithelium with low-grade atypia on gastric cancer after Helicobacter pylori eradiation therapy. J Gastroenterol 
2019;54:907-915.

41. Sunami K, Ichikawa H, Kubo T, et al. Feasibility and utility of a panel testing for 114 cancer-associated genes in a clinical setting: a hospital-based study. Cancer Sci 2019;110:14801490.

42. Dow LE, O’Rourke KP, Simon J, et al. Apc restoration promotes cellular differentiation and reestablishes crypt homeostasis in colorectal cancer. Cell 2015;161:1539-1552.

43. Kato M, Nishida T, Yamamoto K, et al. Scheduled endoscopic surveillance controls secondary cancer after curative endoscopic resection for early gastric cancer: a multicentre retrospective cohort study by Osaka University ESD study group. Gut 2013;62:1425-1432.

44. Maehata Y, Nakamura S, Fujisawa K, et al. Long-term effect of Helicobacter pylori eradication on the development of metachronous gastric cancer after endoscopic resection of early gastric cancer. Gastrointest Endosc 2012;75:39-46.

45. Maehata Y, Nakamura S, Esaki M, et al. Characteristics of primary and metachronous gastric cancers discovered after Helicobacter pylori eradication: a multicenter propensity score-matched study. Gut Liver 2017;11:628-634.

46. Hata $\mathrm{K}$, Ito $\mathrm{M}$, Boda $\mathrm{T}$, et al. gastric cancer with submucosal invasion after successful Helicobacter pylori eradication: a propensity score-matched analysis of patients with annual patient endoscopic survey. Digestion 2019;99:59-65.

47. Kato T, Yagi N, Kamada T, et al. Diagnosis of Helicobacter pylori infection in gastric mucosa by endoscopic features: a multicenter prospective study. Dig Endosc 2013;25:508-518.

48. Nagata N, Shimbo T, Akiyama J, et al. Predictability of gastric intestinal metaplasia by mottled patchy erythema seen on endoscopy. Gastroenterology Res 2011;4:203-209.

49. Haruma K. Kyoto classification of gastritis. Nihon Medical Center: Tokyo, 2017.

50. Moribata K, Iguchi JK, Nakachi K, et al. Endoscopic features associated with development of metachronous gastric cancer in patients who underwent endoscopic resection followed by Helicobacter pylori eradication. Dig Endosc 2016;28:434442.

51. Yao K, Nagahama T, So S, et al. Morphological correlation between ordinary and magnifying endoscopic findings with regard to small, depressed type gastric cancers. Stomach Intestine 2006;41:781-794.

52. Kotachi T, Ito M, Boda $\mathrm{T}$, et al. Clinical significance of reddish depressed lesions observed in the gastric mucosa after Helicobacter pylori eradication. Digestion 2018;98:48-55.

53. Yao K, Anagnostopoulos GK, Ragunath K. Magnifying endoscopy for diagnosing and delineating early gastric cancer. Endoscopy 2009;41:462-467.

54. Yoshifuku Y, Sanomura Y, Oka S, et al. Clinical usefulness of the VS classification system using magnifying endoscopy with blue laser imaging for early gastric cancer. Gastroen- terol Res Pract 2017;2017:3649705.

55. Tahara T, Tahara S, Tuskamoto T, et al. Magnifying NBI patterns of gastric mucosa after Helicobacter pylori eradication and its potential link to the gastric cancer risk. Dig Dis Sci 2017;62:2421-2427.

56. Dohi O, Yagi N, Naito Y, et al. Blue laser imaging-bright improves the real-time detection rate of early gastric cancer: a randomized controlled study. Gastrointest Endosc 2019;89: 47-57.

57. Akazawa Y, Ueyama H, Yao T, et al. Usefulness of demarcation of differentiated-type early gastric cancers after Helicobacter pylori eradication by magnifying endoscopy with narrow-band imaging. Digestion 2018;98:175-184.

58. Kawai T, Ito M, Aoyama N, et al. Evaluation of gastric cancer risk by optimized serum antibody titers against $\mathrm{H}$. pylori: a multi-center retrospective study. Jpn J Helicobacter Res 2018;19:133-138.

59. Okada K, Suzuki S, Naito S, et al. Incidence of metachronous gastric cancer in patients whose primary gastric neoplasms were discovered after Helicobacter pylori eradication. Gastrointest Endosc 2019;89:1152-1159.

60. Shichijo S, Hirata Y, Niikura R, et al. Histologic intestinal metaplasia and endoscopic atrophy are predictors of gastric cancer development after Helicobacter pylori eradication. Gastrointest Endosc 2016;84:618-624.

61. Tahara T, Shibata T, Horiguchi N, et al. A possible link between gastric mucosal atrophy and gastric cancer after Helicobacter pylori eradication. PLoS One 2016;11:e0163700.

62. Toyoshima O, Yamaji Y, Yoshida S, et al. Endoscopic gastric atrophy is strongly associated with gastric cancer development after Helicobacter pylori eradication. Surg Endosc 2017;31:2140-2148.

63. Iguchi M, Kato J, Yoshida T, et al. Serum pepsinogen levels can quantify the risk of development of metachronous gastric cancer after endoscopic resection. Int J Cancer 2016;139: 1150-1156.

64. Mori G, Nakajima T, Asada K, et al. Incidence of and risk factors for metachronous gastric cancer after endoscopic resection and successful Helicobacter pylori eradication: results of a large-scale, multicenter cohort study in Japan. Gastric Cancer 2016;19:911-918.

65. Sugano K, Tack J, Kuipers EJ, et al. Kyoto Global Consensus report on Helicobacter pylori gastritis. Gut 2015;64:13531367.

66. Tahara S, Tahara T, Horiguchi N, et al. DNA methylation accumulation in gastric mucosa adjacent to cancer after Helicobacter pylori eradication. Int J Cancer 2019;144:80-88.

67. Maeda M, Yamashita S, Shimazu T, et al. Novel epigenetic markers for gastric cancer risk stratification in individuals after Helicobacter pylori eradication. Gastric Cancer 2018;21:745-755. 
68. Maeda M, Nakajima T, Oda I, et al. High impact of methylation accumulation on metachronous gastric cancer: 5-year follow-up of a multicentre prospective cohort study. Gut 2017;66:1721-1723.
69. Asada K, Nakajima T, Shimazu T, et al. Demonstration of the usefulness of epigenetic cancer risk prediction by a multicentre prospective cohort study. Gut 2015;64:388-396. 